\title{
Pharmaceutical Technologies for Enhancing Oral Bioavailability of Poorly Soluble Drugs
}

\author{
Yellela S.R. Krishnaiah*
}

College of Pharmacy, Nova Southeastern University, Fort Lauderdale, FL, USA

\begin{abstract}
The oral bioavailability of BCS (biopharmaceutics classification system) class II drugs with poor solubility and reasonable permeability is limited by the drug dissolution step from drug products. Though prodrug approach is an exciting way of improving the oral bioavailability, it requires extensive studies to establish the safety profile of prodrugs in humans. In view of the increasing market share of oral drug products, a variety of technologies are developed to enhance the oral bioavailability of poorly soluble drugs using the excipients with approved or GRAS (generally regarded as safe) status. The present review describes the main technologies such as micronization, nanosizing, crystal engineering, solid dispersions, cyclodextrins, solid lipid nanoparticles and other colloidal drug delivery systems with a few relevant research reports.
\end{abstract}

Keywords: Bioavailability; Oral drug products; Enhancement; Technologies; Dissolution; Micronization; Crystal engineering; Nanosizing; Solid dispersion; Cyclodextrins; Microemulsions; Liposomes

\section{Introduction}

Oral ingestion is the most convenient and commonly employed route of drug delivery due to its ease of administration, high patient compliance, cost-effectiveness, least sterility constraints and flexibility in the design of dosage form. As a result, many of the generic drug companies are inclined more to produce bioequivalent oral drug products. The high costs and time involved in new drug development, expiry of patents for a significant number of drug molecules, ease of manufacturing and ready availability of technology for the production of oral drug products are also driving the generic pharmaceutical companies towards the development of bioequivalent oral dosage forms. However, the major challenge with the design of oral dosage forms lies with their poor bioavailability. The oral bioavailability depends on several factors including aqueous solubility, drug permeability, dissolution rate, first-pass metabolism, pre-systemic metabolism and susceptibility to efflux mechanisms (Sakaeda et al., 2001; Vieth et al., 2004; Wenlock et al., 2003). The most frequent causes of low oral bioavailability is attributed to poor solubility and low permeability (Vieth et al., 2004). The tremendous pharmaceutical research in understanding the causes of low oral bioavailability has led to the development of novel technologies to address these challenges. One of the technologies is to design a prodrug with the required physico-chemical properties to improve the oral bioavailability (Ettmayer et al., 2004). For example, the prodrug approach resulted in improved bioavailability of etilevodopa, caepecitabine, oseltamivir, docarpamine and simvastatin (Djaldetti et al., 2003; Hayden et al., 2000; Mauro, 1993; Milano et al., 2004; Yoshikawa et al., 1995). For BCS class IV drugs with poor solubility and poor membrane permeability and BCS class III drugs with high solubility and low permeability, prodrug approach is the best option to enhance their bioavailability (Gomez-Orellana, 2005). Though prodrug approach is an exciting way of improving the oral bioavailability of BCS class II drugs, it requires extensive studies to establish the safety profile of prodrugs in humans, which ultimately may result in failure. Furthermore, the potential drawback of this approach is the reduced solubility of the prodrug. In today's market, more than $40 \%$ of oral drug products contain poorly soluble drugs, and among the pharmacopoeia, this share is more than 30\% (Giliyar et al., 2006; Lipinski et al., 2001). For these BCS class II drugs with low solubility and reasonable permeability, drug dissolution step is the rate-liming process of drug absorption. When administered as oral dosage forms, the pharmaceutical formulation plays a critical role in the absorption of such drugs from gastrointestinal tract.

A variety of pharmaceutical formulation technologies are used to enhance oral bioavailability of BCS class II drugs. They use already approved excipients and GRAS materials. This in turn reduces the cost and development time. The main technologies to achieve the enhanced oral bioavailability of drugs with poor aqueous solubility include the use of micronization, nanosizing, crystal engineering, solid dispersions, cyclodextrins, solid lipid nanoparticles and other colloidal drug delivery systems such as microemulsions, self-emulsifying drug delivery systems, selfmicroemulsifying drug delivery systems and liposomes (Fahr and Liu, 2007; Gomez-Orellana, 2005). A brief review of the technologies along with a few reports is presented to emphasize their importance in enhancing the oral bioavailability of poorly soluble drugs.

\section{Micronization}

The oral bioavailability of drugs presented in a solid dosage form depends mainly on size, size distribution and morphology of particles. This is due to enhanced surface area of drug particles available for dissolution. Hence, a variety of micronization technologies such as spray-drying, freeze-drying, crystallization *Corresponding author: Yellela S.R. Krishnaiah, PhD, Associate Profes-
sor of Pharmaceutics, Department of Pharmaceutical Sciences, College of
Pharmacy, Nova Southeastern University, 3200, South University Drive, Fort
Lauderdale, FL 33328, USA, Tel: 954-262-1529 (O); Fax: 954-262-2278
Received January 29, 2010; Accepted March 30, 2010; Published
March 30, 2010
Citation: Krishnaiah YSR (2010) Pharmaceutical Technologies for Enhanc-
ing Oral Bioavailability of Poorly Soluble Drugs. J Bioequiv Availab 2: 028-
036. doi:10.4172/jbb.1000027
Copyright: @ 2010 Krishnaiah YSR. This is an open-access article distrib-
uted under the terms of the Creative Commons Attribution License, which
permits unrestricted use, distribution, and reproduction in any medium, pro-
vided the original author and source are credited.

J Bioequiv Availab

ISSN:0975-0851 JBB, an open access journal
Volume 2(2): 028-036 (2010) - 028 
Citation: Krishnaiah YSR (2010) Pharmaceutical Technologies for Enhancing Oral Bioavailability of Poorly Soluble Drugs. J Bioequiv Availab 2: 028-036. doi:10.4172/jbb.1000027

and milling processes were developed to decrease the particle size. However, the disadvantages associated with these traditional technologies are production of coarse particles with broad size distribution, degradation of the product due to thermal or mechanical stress and contamination of the particles with toxic solvents. In the recent times, supercritical fluid (SCF) technologies are developed to overcome these disadvantages so as to produce a solvent-free drug product with improved dissolution, bioavailability and stability (Kompella and Koushik, 2001; Vemavarapu et al., 2005; York, 1999). These greener SCF technologies have been demonstrated to produce particles with residual solvent content below the FDA-permitted levels (Steckel et al., 1997). Furthermore, control over the morphology and crystallographic purity of the particles is shown to be better than several other conventionally used processes (Beach et al., 1999).

The various SCF processes are Supercritical Antisolvent System (SAS), Rapid Expansion of Supercritical Solutions (RESS), Particles from Gas-Saturated Systems (PGSS), Gas Antisolvent System (GAS), Precipitation using Compressed Antisolvent (PCA), Solution Enhanced Dispersion by Supercritical fluids (SEDS) etc. In all these processes, SCF basically acts as precipitation agent producing solvent-free drug particles. In RESS, it acts like a solvent whereas in SAS, PCA and SEDS it acts like an antisolvent. Typically, in an SAS process, a mixture of drug and carrier are dissolved in a solvent, and then sprayed through a nozzle into a high pressure chamber filled with SCF. As each droplet is formed in the high pressure vessel, the SCF extracts the solvent leaving behind a solvent-free drug powder. By manipulating the temperature, pressure and concentration of supercritical fluids, and nozzle design one can produce a variety of powder sizes. A good number of reports appear in the literature wherein SCF technologies are used for improving the dissolution rate of drugs such as nifedipine, felodipine, fenofibrate, atorvastatin, itraconazole, budesonide and carbamazepine (Kerc et al., 1999; Kim et al., 2008; Lee et al., 2005; Liu et al., 2007; Salmaso et al., 2009; SencarBozic et al., 1997; Sethia and Squillante, 2002; Yamanaka and Leong, 2008). The scale-up of these novel SCF technologies is on its way for industrial production of micronized particles in drug delivery.

\section{Nanosizing}

This involves the reduction of drug particle size to the submicron range. The advances in milling technologies made it possible to produce drug particles in the range of 100 to $200 \mathrm{~nm}$ in a reproducible manner. While reduction of particle size has been employed in pharmaceutical industry for several decades, nanosizing can provide a further enhancement of dissolution rate. Nanosizing involves mechanical attrition to render large crystalline particles into nanoparticles. Elan's NanoCrystal ${ }^{\circledR}$ wetmilling technology and SkyePharma’s Dissocubes ${ }^{\circledR}$ high-pressure homogenization technology utilize these principles for producing nanoparticles (Keck and Muller, 2006; MeriskoLiversidge et al., 2003; Muller et al., 2001). An important requirement is that the nanoparticles are to be stabilized and formulated rigorously to retain their nature and properties (MeriskoLiversidge et al., 2003). This is achieved with surfactants or polymers in nanosuspensions which can be further processed into standard dosage forms such as capsules or tablets suitable for oral administration. These nanoformulations offer increased dissolution rates for drug compounds and complement other technologies used to enhance bioavailability of insoluble compounds (BCS Class II and IV drugs) such as solubility enhancers (i.e. surfactants), liquid-filled capsules or solid dispersions of drugs in their amorphous state (Kesisoglou et al., 2007).

Elan's NanoCrystal ${ }^{\circledR}$ technology can reduce crystalline particle size to $<100-250 \mathrm{~nm}$. The drawback of this technique is that the milling process often requires grinding for hours to days in order to reach the desired size range. In high-pressure homogenization method, a jet-milled product is dispersed in an aqueous surfactant solution by high-speed stirring. The obtained macro-suspension is passed through a high-pressure homogenizer applying typically 1500 bar and three to ten homogenization cycles. The suspension passes a very small gap in the homogenizer. Due to the narrowness of the gap, the streaming velocity of the suspension increases tremendously, which means the dynamic fluid pressure increases. Simultaneously, the static pressure on the fluid decreases below the boiling point of water at room temperature. Consequently, water starts boiling at room temperature due to the high pressure, and gas bubbles are formed, which implode when the fluid leaves the homogenization gap. These cavitation forces are strong enough to break drug microparticles into drug nanoparticles (Muller et al., 2001). Many reports in the literature have demonstrated the advantage of nanoformulations over micronized drugs in improving oral bioavailability (Dai et al., 2007; Fakes et al., 2009; Yang et al., 2010). The success of the nanosizing technologies is exemplified by the marketability of drugs such as sirolimus, fenofibrate, aprepitant and megestrol acetate (Kesisoglou et al., 2007). Before considering the application of nanosizing to enhance the oral bioavailability, the biopharmaceutical properties of the drug are to be carefully evaluated. Drugs exhibiting dissolution ratelimited absorption are the best candidates for nanosizing. It is anticipated that nanosizing will attract increased attention in formulating fast dissolving oral dosage forms.

\section{Crystal engineering}

The surface area of drug available for dissolution is dependent on its particle size and ability to be wetted by luminal fluids. This particle size, which is critical to drug dissolution rate, is dependent on the conditions of crystallization or on methods of comminution such as impact milling and fluid energy milling. The comminution techniques can produce particles which are highly heterogeneous, charged and cohesive, with the potential to cause problems in downstream processing and product performance. Hence, crystal engineering techniques are developed for the controlled crystallization of drugs to produce high purity powders with well defined particle size distribution, crystal habit, crystal form (crystalline or amorphous), surface nature and surface energy (Blagden et al., 2007). By manipulating the crystallization conditions (use of different solvents or change in the stirring or adding other components to crystallizing drug solution), it is possible to prepare crystals with different packing arrangement; such crystals are called polymorphs. As a result, polymorphs for the same drug may differ in their physico-chemical properties such as solubility, dissolution rate, melting point and stability. Most drugs exhibit structural polymorphism and it is preferable to develop the most thermodynamically stable polymorph of the drug to assure reproducible 


\section{Journal of Bioequivalence \& Bioavailability - Open Access}

JBB/Vol.2 Issue 2

bioavailability of the product over its shelf-life under a variety of real-world storage conditions. A classic example of the importance of polymorphism on bioavailability is that of chloramphenicol palmitate suspensions. It was shown that the stable $\alpha$ polymorph of chloramphenical palimitate produced low serum levels, whereas the metastable $\beta$-polymorph yielded much higher serum levels when the same dose was administered (Aguiar et al., 1967). In another study, it was found that tablets prepared from the form $A$ polymorph of oxytetracycline dissolved significantly more slowly than the tablets with form $B$ polymorph of the same drug (Liebenberg et al., 1999). The tablets with form $A$ polymorph exhibited about $55 \%$ dissolution at $30 \mathrm{~min}$, while the tablets with form $B$ polymorph exhibited almost complete $(95 \%)$ dissolution at the same time (30 $\mathrm{min})$.

Crystal engineering approach also involves the preparation of hydrates and solvates for enhancing the dissolution rate. During the crystallization process, it is possible to trap molecules of the solvent within the lattice. If the solvent used is water, the material is described as hydrate. If solvents other than water are present in a crystal lattice, the material is called a solvate. The dissolution rate and solubility of a drug can differ significantly for different solvates. For example, glibenclamide has been isolated as pentanol and toluene solvates, and these solvates exhibited higher solubility and dissolution rate than two non-solvated polymorphs (Suleiman and Najib, 1989). It is possible for the hydrates to have either a faster or slower dissolution rate than the anhydrous form. The most usual situation is for the anhydrous form to have a faster dissolution rate than the hydrate. For example, the dissolution rate of theophylline anhydrate was faster than its hydrate form (Shefter and Higuchi, 1963). In certain cases, hydrate form of the drug may show rapid dissolution rate than its anhydrous form. Erythromycin dihyrate was found to exhibit significant differences in the dissolution rate when compared to monohydrate and anhydrate form (Allen et al., 1978). In general, it is undesirable to use solvates for drugs and pharmaceuticals as the presence of organic solvent residues may be toxic.

Crystal engineering offers a number of routes to improved solubility and dissolution rate, which can be adopted through an in-depth knowledge of crystallization processes and the molecular properties of active pharmaceutical ingredients. The process involves dissolving the drug in a solvent and precipitating it in a controlled manner to produce nanoparticles through addition of an anti-solvent (usually, water) (Blagden et al., 2007). This technology is available from DowPharma (Midland, MI, USA) and BASF Pharma Solutions (Florham Park, NJ, USA). Pharmaceutical co-crystals open a new avenue to address the problems of poorly soluble drugs. They contain two or more distinct molecules arranged to create a new crystal form whose properties are often superior to those of each of the separate entities. The pharmaceutical co-crystals are formed between a molecular or ionic drug and a co-crystal former that is a solid under ambient conditions (Vishweshwar et al., 2006). These are prepared by slow evaporation from a drug solution containing stoichiometric amounts of the components (cocrystal formers); however, sublimation, growth from the melt, or grinding of two or more solid cocrystal formers in a ball mill are also suitable methodologies (Shan and Zaworotko, 2008). Carbamazepine:saccharin co-crystal was shown to be superior to existing crystal forms of carbamazepine in terms of stability, dissolution, suspension stability and oral absorption profile in dogs (Hickey et al., 2007). In another study, fluoxetine $\mathrm{HCl}$ :succinic acid cocrystal was found to exhibit an approximately twofold increase in aqueous solubility after only $5 \mathrm{~min}$ (Childs et al., 2004). A number of stable pharmaceutical cocrystals of itraconazole and 1,4-dicarboxylic acids were synthesized and crystallographically characterized (Remenar et al., 2003). It was noted that the itraconazole:L-malic acid cocrystal exhibited a similar dissolution profile to that of the marketed formulation.

Traditional crystallization methods include sublimation, crystallization from solutions, evaporation, thermal treatment, desolvation, or grinding/milling. These are being replaced with novel methods of crystal engineering techniques such as $S C F$ technologies (Moribe et al., 2008; Pasquali et al., 2008) to produce pharmaceutical solids with desired dissolution rate and stability. Melt sonocrystallization is yet another emerging technology that uses ultrasonic energy to produce porous fast dissolving particles for hydrophobic drug molecules (Paradkar et al., 2006). Based on these exciting reports, it appears that crystal engineering techniques need to be exploited more for enhancing the dissolution rate of poorly soluble drugs.

\section{Solid dispersion}

The effective surface area is one of the important factors governing the dissolution rate of poorly soluble drugs. In addition to the micronization and nanosizing technologies, as described above, solid dispersion is the other way of enhancing the effective surface area available for dissolution (Chiou and Riegelman, 1971; Serajuddin, 1999). Solid dispersion involves the dispersion of one or more active ingredients in an inert carrier or matrix at solid state. These are usually prepared by heating mixtures of the drug and carrier to a molten state, followed by resolidification by way of cooling. A solid dispersion of nitrendipine prepared by a melt-mixing method using silica particles as carriers showed remarkably improved dissolution properties compared with that of the original nitrendipine crystals (Wang et al., 2006). This melt method often requires relatively high temperatures $\left(>100^{\circ} \mathrm{C}\right)$, which may lead to thermal degradation of the drug. Solvent evaporation method is another technique of preparing solid dispersions which involves dissolving the components in a mutual volatile solvent followed by evaporation. Sometimes, drug is dissolved in a solvent such as propylene glycol and the resulting solution is added to the molten carrier. Solid dispersions of spironolactone, itraconazole and prednisolone, prepared by solvent evaporation method, were shown to enhance their dissolution rate (Leonardi et al., 2007; Uchino et al., 2007; Wang et al., 2004). The solvent evaporation method has several disadvantages (Bloch and Speiser, 1987). It is time-consuming and expensive because of long processing and drying times. Moreover, it is not environment-friendly due to the use of organic solvents, and may have toxic residual solvent(s) in the final product.

As described under micronization approach, the SCF technologies involving mild processing conditions of low temperatures $\left(\sim 30^{\circ} \mathrm{C}\right)$ and minimal or no organic solvents are considered the most promising to overcome the disadvantages associated with the melt and solvent evaporation methods of prepar- 
Citation: Krishnaiah YSR (2010) Pharmaceutical Technologies for Enhancing Oral Bioavailability of Poorly Soluble Drugs. J Bioequiv Availab 2: 028-036. doi:10.4172/jbb.1000027

ing solid dispersions (Yasuji et al., 2008). For example, the dissolution rate and stability profile of felodipine and carbamazepine prepared using SCF technologies were found superior to those prepared using conventional solvent evaporation method (Sethia and Squillante, 2004; Won et al., 2005). Another interesting approach of producing solid dispersion without the use of organic solvents is the use of melt extrusion technology. In this process, heat is used to make thermoplastic materials pliable enough to incorporate drug particles in the polymer matrix. Intensive mixing is achieved through the shear stress created by the shear rate used. The decomposition of the drug and/ or carrier is unlikely with melt extrusion technology as the processing temperature is lower than the melting point of the drug and the softening temperature of the polymer (carrier). The dissolution profile and stability of several drugs including $17 \beta$-estradiol, itraconazole and nitrendipine solid dispersions were improved when prepared using melt extrusion technology (Hulsmann et al., 2001; Hulsmann et al., 2000; Tao et al., 2009; Verreck et al., 2003; Wang et al., 2005). The melt extrusion technology is considered to be an efficient technique in developing solid molecular dispersions and has been demonstrated to provide sustained, modified and targeted drug delivery resulting in enhanced bioavailability (Repka et al., 2008). Sustained release tablets of verapamil prepared with melt extrusion technology were resistant to the effects of ethanol on in vitro dose dumping when combined with readily accessible ethanol concentrations (Roth et al., 2009). The vast number of reports on solid dispersion research could bring out the industrially feasible technologies such as melt extrusion technology and SCF technology for the production of solid dosage forms with improved oral bioavailability. This is highly beneficial to BCS class II drugs as the enhanced dissolution increases permeation through the gut wall. In contrast, BCS class IV drugs may not gain from fast dissolution, as a lower permeation may cause the recrystallization of the drug after dissolution in the gut environment (Fahr and Liu, 2007).

\section{Cyclodextrins}

These starch derivatives are the most widely investigated excipients for enhancing the solubility and dissolution rate of poorly soluble drugs. The interior of these molecules is relatively lipophilic and the exterior relatively hydrophilic. Cyclodextrins and their commercially available derivatives are able to incorporate apolar molecules or parts of molecules inside their hydrophobic cavity resulting in better stability, high water solubility, increased bioavailability or decreased undesirable side effects (Duchene et al., 1999). The mechanism for the enhanced solubilization is entrenched in the ability of cyclodextrin to form non-covalent dynamic inclusion complexes in solution. Other solubilizing attribute may include the ability to form non-inclusion based complexes, the formation of aggregates and related domains and the ability of cyclodextrins to form and stabilize supersaturated drug solutions (Brewster and Loftsson, 2007). Though $\beta$ cyclodextrin was the first cyclodextrin used to enhance the dissolution rate of poorly soluble drugs, its low aqueous solubility together with its nephrotoxicity prompted the development of high water soluble and less toxic derivates such as 2hydroxypropyl- $\beta$-cyclodextrin, methyl- $\beta$-cyclodextrin and sulfobutyl ether- $\beta$-cyclodextrin (Fahr and Liu, 2007; Stella and
Rajewski, 1997; Szente and Szejtli, 1999). The increase in solubility also can increase dissolution rate and thus improve the oral bioavailability of BCS Class II drugs. The success rate of cyclodextrins for enhancing the dissolution rate of poorly soluble drugs is witnessed by the presence of over 35 marketed drug products incorporating them as excipients. The examples include itraconazole-hydroxypropyl- $\beta$-cyclodextrin, piroxicam- $\beta$ cyclodextrin and benexate- $\beta$-cyclodextrin (Fahr and Liu, 2007). The inclusion complexes of acelofenac with hydroxypropyl- $\beta$ cyclodextrin prepared by spray drying process were shown to provide enhanced dissolution rate as well as improved anti-inflammatory activity (Ranpise et al., 2010).

The solubilizing ability of cyclodextrins can be further enhanced by incorporating other water-soluble excipients. For example, the association of water-soluble polymer PEG4000 with glimepiride-2-hydroxypropyl- $\beta$-cyclodextrin systems has shown a greatly enhanced dissolution rate, increased duration of action and improvement of therapeutic efficacy of the drug (Ammar et al., 2006). The drug-cyclodextrin complexes are prepared by freeze-drying, spray-drying, and co-precipitation of a cyclodextrin/drug solution or simple grinding the slurry of drug and cyclodextrin (Carrier et al., 2007). These methods may involve one or more organic solvent and thus the final product may contain residual toxic solvents. The difference in complex formation methodology can affect the dissolution kinetics and subsequently the bioavailability. This may be due to the differences in the extent of complex formation, changes in the particle size and degree of amorphous nature of the resulting material. Hence, it is essential to carefully control the processing variables while preparing the drug-cyclodextrin complexes (Miller et al., 2007). This could be achieved using the latest technologies such as SCF processing methods (Al-Marzouqi et al., 2009; Hassan et al., 2007; Hussein et al., 2007).

\section{Solid lipid nanoparticles}

Solid lipid nanoparticles (SLN) represent an alternative carrier system to traditional colloidal carriers (emulsions, liposomes and polymeric micro- and nanoparticles) in enhancing the oral bioavailability of poorly soluble drugs. These particulate systems contain solid lipids as matrix material which possesses adhesive properties that make them adhere to the gut wall and release the drug exactly where it should be absorbed (Muller and Keck, 2004). In addition, the lipids are known to have properties that promote the oral absorption of lipophilic drugs and drugs in general (Charman, 2000). Thus, SLN can improve the oral bioavailability of the poorly soluble drugs. Of the available methods, high-pressure homogenization and microemulsion technology are considered as the most feasible methods for large scale production of SLN (Muchow et al., 2008; Muller et al., 2000). Lipid matrix of solid lipid nanoparticles is made from physiologically tolerated lipid components, which decreases the potential for acute and chronic toxicity (Mehnert and Mader, 2001). Another significant advantage of SLN formulations is that they have the ability to be stable for 3 years, which is of paramount importance with respect to colloidal drug carriers (Freitas and Muller, 1998). There are a number of reports indicating the enhanced oral bioavailability of drugs including praziquantel, quercetin, lovastatin, nitrendipine, vinpocetine and cyclosporine (Kumar et al., 2007; Li et al., 2009; Luo et al., 


\section{Journal of Bioequivalence \& Bioavailability - Open Access}

JBB/Vol.2 Issue 2

2006; Muchow et al., 2008; Muller et al., 2006; Suresh et al., 2007; Yang et al., 2009). The potential of these SLN is indicated by the efforts of pharmaceutical companies (SkyePharma AG, Muttenz, Switzerland and Vectorpharma, Trieste, Italy) to produce commercially feasible products through their own technologies.

\section{Other colloidal drug delivery systems}

These include the emulsified systems as well as liposomes. Traditional emulsions, microemulsions, self-emulsified drug delivery systems and self-microemulsifying drug delivery systems belong to emulsified systems. The formulation of emulsions involves the use of digestible oils such as cottonseed oil and soybean oil. The enhanced drug absorption from an emulsion is a widely known concept. For example, the oral bioavailability of griseofulvin from a corn oil emulsion formulation was found to be twofold in humans when compared with either an aqueous suspension or commercial tablet formulation (Bates and Sequeria, 1975). However, emulsions are known for their thermodynamic instability. This drawback can be eliminated by converting the liquid emulsions into solid emulsion powder by means of a suitable technique such as spray drying. These dry emulsions are cohesive and bulky, and hence formulated as tablets or capsules. Comparable bioavailability were obtained from dry emulsion powder and oral dosage form (tablet and capsule) when a model drug ( $\mathrm{Lu} \mathrm{28-179)}$ was formulated and administered to beagle dogs (Hansen et al., 2005). The emulsions are cloudy, thermodynamically unstable and requires high amount of energy for producing them. Microemulsions are novel pharmaceutical formulations designed to overcome the above disadvantages. They are thermodynamically stable, transparent, low viscosity, easy to prepare and isotropic dispersions consisting of oil and water stabilized by an interfacial film of surfactant molecules, typically in conjunction with a cosurfactant. It is possible to incorporate water-soluble, oil-soluble and amphiphilic drugs into microemulsions. For example, while formulating a microemulsion, water-insoluble lipophilic drugs can be incorporated into the disperse oil phase and/ or hydrophobic tail region of the surfactant and the hydrophilic drug can be incorporated into disperse aqueous phase of water-in-oil droplet.

For enhancing the solubility and dissolution rate of poorly soluble drugs, it is preferable to formulate them as oil-in-water microemulsions instead of water-in-oil microemulsions (Lawrence and Rees, 2000). This is because the droplet structure of oil-in-water microemulsions is often retained on dilution by aqueous biological fluid thereby enhances oral bioavailability. In contrast, if formulated as water-in-oil microemulsions, the droplet size increases on dilution in GI tract, and ultimately results in dose dumping due to phase separation. Microemulsion systems are widely used to improve the solubility and absorption of poorly water-soluble drugs. In one of the studies, microemulsions with varying weight ratios of surfactant to cosurfactant were prepared using caprylic/capric triglyceride as oil, polyoxyethylated castor oil as a surfactant, Transcutol ${ }^{\circledR}$ as a cosurfactant and saline (Gao et al., 1998). The absolute bioavailability of cyclosporine loaded in this microemulsion system was increased about 3.3 and 1.25 fold compared with Sandimmun ${ }^{\circledR}$ and Sandimmun Neoral ${ }^{\circledR}$. The enhanced bioavailability of cyclosporine loaded in this microemulsion system were considered due to the reduced droplet size of microemulsion systems (Gao et al., 1998). A microemulsion system of docetaxel was prepared and evaluated for its solubilization capacity and oral bioavailability improvement (Yin et al., 2009). The oil-in-water microemulsion formulation composed of Capryol 90 (oil), Cremophor EL (surfactant) and Transcutol (co-surfactant) enhanced the solubility of docetaxel up to $30 \mathrm{mg} / \mathrm{mL}$, which maintained solubilization capacity for $24 \mathrm{~h}$ even after it was diluted 20 times with normal saline. The oral bioavailability of the microemulsion formulation in rats $(34.42 \%)$ rose dramatically compared to that of the orally administered Taxotere ${ }^{\circledR}(6.63 \%)$. The studies showed that combined effect of the enhancement in solubility, the inhibition of P-gp efflux system and the increase in permeability might have increased the bioavailability of docetaxel (Yin et al., 2009). In another study, microemulsion formulation of puerarin, prepared with soybean oil, soybean lecithin/ethyl lactate (1:1) and 1,2-propanediol/water, was shown to be stable with enhanced oral bioavailability when compared to suspension formulation (Wu et al., 2009).

Self-emulsifying drug delivery systems (SEDDS) and selfmicroemulsifying drug delivery systems (SMEDDS) are isotropic solutions of oil and surfactant which form oil-in-water microemulsions on mild agitation in the presence of water (Shah et al., 1994). The poorly soluble drug can be dissolved in a mixture of surfactant and oil which is widely known as preconcentrate. These novel colloidal formulations on oral administration behave like oil-in-water microemulsions. Compared with ready-to-use microemulsions, the SEDDS and SMEDDS have been shown to improve physical stability profile in longterm storage. SEDDS have been reported to enhance the oral bioavailability of paclitaxel, griseofulvin and dexibuprofen (Arida et al., 2007; Balakrishnan et al., 2009; Gao et al., 2003). Similarly, SMEDDS were shown to enhance the oral bioavailability of poorly soluble drugs such as simvastatin, acyclovir and exemestane (Kang et al., 2004; Patel and Sawant, 2007; Singh et al., 2009). Solid SEDDS are the advanced formulations that can be filled directly into soft or hard gelatin capsules for conventional drug delivery (Tang et al., 2008). For example, solid SEDDS of dexibuprofen, prepared by spray drying of liquid SEDDS with an inert solid carrier Aerosil 200, showed twofold increase in the oral bioavailability when compared to the powder form (Balakrishnan et al., 2009).

One of the challenges in formulating microemulsions, SEDDS or SMEDDS is the limited availability of formulation components with GRAS status. In this context, liposomal formulations may be preferred over the above colloidal drug delivery systems for solubilizing the drugs and thereby to enhance oral bioavailability (Fahr et al., 2005). This is because of the GRAS status of phospholipid constituents used in liposomal formulations. Liposomes are phospholipid vesicles, comprising a phospholipid bilayer surrounding an aqueous compartment. In the lipid domain of the bilayer membrane, lipophilic drugs can be dissolved. Due to their biphasic characteristic and diversity in design, composition and construction, liposomes offer a dynamic and adaptable technology for enhancing drug solubility (Fahr and Liu, 2007). It has been reported that the liposome encapsulation efficiency of lipophilic drugs depends on both the 
Citation: Krishnaiah YSR (2010) Pharmaceutical Technologies for Enhancing Oral Bioavailability of Poorly Soluble Drugs. J Bioequiv Availab 2: 028-036. doi:10.4172/jbb.1000027

physicochemical properties of the drug, such as its lipophilicity, and on factors including bilayer composition and the method of preparation (Fresta et al., 1993). Liposomes are shown to be promising carriers for enhancing the bioavailability of poorly soluble drugs such as ibuprofen, amphotericin B, cyclosporine, and griseofulvin (Dupont, 2002; Fahr and Seelig, 2001; Mohammed et al., 2004; Stozek and Borysiewicz, 1991). A fenofibrate liposomal formulation was prepared by a dry-film dispersing method coupled with sonication and homogenization using soybean phosphotidylcholine and sodium deoxycholate or cholesterol (Chen et al., 2009). In vivo measurements of pharmacokinetics and bioavailability demonstrated higher rates of fenofibrate absorption from the liposomal formulations than micronized fenofibrate.

\section{Conclusions}

In view of the increasing market share of oral drug products, pharmaceutical companies are focusing their research to resolve the issue of poor drug solubility through the development of novel technologies. Though prodrug approach is an exciting way of improving the oral bioavailability of BCS class II drugs with low solubility and reasonable permeability, it requires extensive studies to establish the safety profile of prodrugs in humans. The traditional methods of micronization are likely to be replaced with greener SCF technologies that can have a precise control over the particle size and distribution and product quality (solvent-free) with improved dissolution, bioavailability and stability. The scale-up of SCF technologies is on its way for industrial production of micronized particles for enhancing the bioavailability of poorly soluble drugs. The advancements in milling technologies (e.g. Elan's NanoCrystal ${ }^{\circledR}$ technology) could result in the production of nanosized drug particles in the range of 100 to $200 \mathrm{~nm}$ in a reproducible manner. The success of the nanosizing technologies is exemplified by the marketability of drugs such as sirolimus, fenofibrate, aprepitant and megestrol acetate. Crystal engineering techniques (e.g. SCF technologies) are developed for the controlled crystallization of drugs to produce polymorphs, hydrates, solvates, nanoparticles and pharmaceutical co-crystals with enhanced oral bioavailability. Melt sonocrystallization is another emerging technology that uses ultrasonic energy to produce porous fast dissolving particles for BCS class II drugs.

The vast amount of research on the use of solid dispersion technique for enhancing the dissolution rate of poorly soluble drugs has paved the way for the development of novel technologies such as melt extrusion technology and SCF technologies. These technologies are able to overcome the disadvantages associated with traditional methods of preparing solid dispersions (melt method and solvent evaporation method). Cyclodextrins and their commercially available derivatives are able to incorporate poorly soluble drugs or parts of molecules inside their hydrophobic cavity resulting in high water solubility and increased bioavailability. The solubilizing ability of these cyclodextrins can be further enhanced by incorporating other water-soluble excipients. Like solid dispersions, the traditional methods of preparing drug-cyclodextrin complexes involve the use of one or more organic solvents, and thus the final product may contain residual toxic solvents. The SCF technologies appear to be the most promising to eliminate the use of organic solvents in preparing drug-cyclodextrin complexes. The solid lipid nanoparticles are able to entrap lipophilic drugs and stick to the gut wall resulting in enhanced oral bioavailability. Of the available methods, high-pressure homogenization and microemulsion technology are considered as the most feasible methods for large scale production of SLN. The potential of these SLN is indicated by the efforts of pharmaceutical companies (SkyePharma AG, Muttenz, Switzerland and Vectorpharma, Trieste, Italy) to produce commercially feasible products through their own technologies.

Microemulsions are novel pharmaceutical formulations are thermodynamically stable, transparent, low viscosity, easy to prepare and isotropic dispersions designed to enhance the oral bioavailability of poorly soluble drugs. SEDDS and SMEDDS are isotropic solutions of oil and surfactant which form oil-inwater microemulsions in GI tract after mixing with biological fluids. The poorly soluble drugs can be incorporated in the oil phase to enhance their oral bioavailability. One of the challenges in formulating microemulsions, SEDDS or SMEDDS is the limited availability of formulation components with GRAS status. In this context, liposomal formulations may be preferred over the SEDDS and SMEDDS for solubilizing the drugs and thereby to enhance oral bioavailability. This is because of the GRAS status of phospholipid constituents used in liposomal formulations. The excellent research reports from academia and pharmaceutical industry are continuously encouraging the development of industrially feasible technologies for producing quality products with enhanced oral bioavailability of poorly soluble drugs.

\section{References}

1. Aguiar AJ, Krc J Jr, Kinkel AW, Samyn JC (1967) Effect of polymorphism on the absorption of chloramphenicol from chloramphenicol palmitate. J Pharm Sci 56: 847-853. »CrossRef » PubMed » Google Scholar

2. Al-Marzouqi AH, Elwy HM, Shehadi I, Adem A (2009) Physicochemical properties of antifungal drug-cyclodextrin complexes prepared by supercritical carbon dioxide and by conventional techniques. J Pharm Biomed Anal 49: $227-$ 233. »CrossRef » PubMed » Google Scholar

3. Allen PV, Rahn PD, Sarapu AC, Vanderwielen AJ (1978) Physical characterization of erythromycin: anhydrate, monohydrate, and dihydrate crystalline solids. J Pharm Sci 67: 1087-1093. » CrossRef » PubMed » Google Scholar

4. Ammar HO, Salama HA, Ghorab M, Mahmoud AA (2006) Formulation and biological evaluation of glimepiride-cyclodextrin-polymer systems. Int J Pharm 309: 129-138. »CrossRef » PubMed » Google Scholar

5. Arida AI, Al-Tabakha MM, Hamoury HAJ (2007) Improving the high variable bioavailability of griseofulvin by SEDDS. Chem Pharm Bull 55: 1713-1719. »CrossRef » PubMed » Google Scholar

6. Balakrishnan P, Lee BJ, Oh DH, Kim JO, Hong MJ, et al. (2009) Enhanced oral bioavailability of dexibuprofen by a novel solid Self-emulsifying drug delivery system (SEDDS). Eur J Pharm Biopharm 72: 539-545. »CrossRef » PubMed » Google Scholar

7. Bates TR, Sequeria JA (1975) Bioavailability of micronized griseofulvin from corn oil-in-water emulsion, aqueous suspension, and commercial tablet dosage forms in humans. J Pharm Sci 64: 793-797. » CrossRef » PubMed » Google Scholar

8. Beach S, Latham D, Sidgwick C, Hanna M, York P (1999) Control of the physical form of salmeterol xinofoate. Org Process Res Dev 3: 370-376. » CrossRef » PubMed » Google Scholar

9. Blagden N, de Matas M, Gavan PT, York P (2007) Crystal engineering of active pharmaceutical ingredients to improve solubility and dissolution rates. Adv Drug Deliv Rev 9: 617-630. » CrossRef » PubMed » Google Scholar

J Bioequiv Availab

Volume 2(2): 028-036 (2010) - 033

ISSN:0975-0851 JBB, an open access journal 


\section{Journal of Bioequivalence \& Bioavailability - Open Access \\ JBB/Vol.2 Issue 2}

10. Bloch DW, Speiser PP (1987) Solid Dispersions - Fundamentals and Examples. Pharm Acta Helv 62: 23-27. » CrossRef » PubMed » Google Scholar

11. Brewster ME, Loftsson T (2007) Cyclodextrins as pharmaceutical solubilizers. Adv Drug Deliv Rev 59: 645-666. » CrossRef » PubMed » Google Scholar

12. Carrier RL, Miller LA, Ahmed I (2007) The utility of cyclodextrins for enhancing oral bioavailability. J Control Release 123: 78-99. »CrossRef » PubMed » Google Scholar

13. Charman WN (2000) Lipids, lipophilic drugs, and oral drug delivery-some emerging concepts. J Pharm Sci 89: 967-978. » CrossRef » PubMed » Google Scholar

14. Chen Y, Lu Y, Chen J, Lai J, Sun J, et al. (2009) Enhanced bioavailability of the poorly water-soluble drug fenofibrate by using liposomes containing a bile salt. Int J Pharm 376: 153-160. » CrossRef » PubMed » Google Scholar

15. Childs SL, Chyall LJ, Dunlap JT, Smolenskaya VN, Stahly BC, et al. (2004) Crystal engineering approach to forming cocrystals of amine hydrochlorides with organic acids. Molecular complexes of fluoxetine hydrochloride with benzoic, succinic, and fumaric acids. J Am Chem Soc 126: 13335-13342. »CrossRef » PubMed » Google Scholar

16. Chiou WL, Riegelman S (1971) Pharmaceutical applications of solid dispersion systems. J Pharm Sci 60: 1281-1302. »CrossRef » PubMed » Google Scholar

17. Dai WG, Dong LC, Song YQ (2007) Nanosizing of a drug/carrageenan complex to increase solubility and dissolution rate. Int J Pharm 342: 201-207. »CrossRef » PubMed » Google Scholar

18. Djaldetti R, Giladi N, Hassin-Baer S, Shabtai H, Melamed E (2003) Pharmacokinetics of etilevodopa compared to levodopa in patients with Parkinson's disease: an open-label, randomized, crossover study. Clin Neuropharmacol 26: 322326. » CrossRef » PubMed » Google Scholar

19. Duchene D, Wouessidjewe D, Ponchel G (1999) Cyclodextrins and carrier systems. J Control Release 62: 263-268. »CrossRef » PubMed » Google Scholar

20. Dupont B (2002) Overview of the lipid formulations of amphotericin B. J Antimicrob Chemother 49: 31-36. » CrossRef » PubMed » Google Scholar

21. Ettmayer P, Amidon GL, Clement B, Testa B (2004) Lessons learned from marketed and investigational prodrugs. J Med Chem 47: 2393-2404.»CrossRef » PubMed » Google Scholar

22. Fahr A, Liu X (2007) Drug delivery strategies for poorly water-soluble drugs. Expert Opin Drug Deliv 4: 403-416. » CrossRef » PubMed » Google Scholar

23. Fahr A, Seelig J (2001) Liposomal formulations of Cyclosporin A: a biophysical approach to pharmacokinetics and pharmacodynamics. Crit Rev Ther Drug Carrier Syst 18: 141-172. »CrossRef » PubMed » Google Scholar

24. Fahr A, van Hoogevest P, May S, Bergstrand N, ML SL (2005) Transfer of lipophilic drugs between liposomal membranes and biological interfaces: consequences for drug delivery. Eur J Pharm Sci 26: 251-265. » CrossRef » PubMed » Google Scholar

25. Fakes MG, Vakkalagadda BJ, Qian F, Desikan S, Gandhi RB, et al. (2009) Enhancement of oral bioavailability of an HIV-attachment inhibitor by nanosizing and amorphous formulation approaches. Int J Pharm 370: 167-174. » CrossRef » PubMed » Google Scholar

26. Freitas C, Muller RH (1998) Effect of light and temperature on zeta potential and physical stability in solid lipid nanoparticle (SLN (TM)) dispersions. Int J Pharm 168: 221-229. » CrossRef » PubMed » Google Scholar

27. Fresta M, Villari A, Puglisi G, Cavallaro G (1993) 5-Fluorouracil - Various Kinds of Loaded Liposomes - Encapsulation Efficiency, Storage Stability and Fusogenic Properties. Int J Pharm 99: 145-156. CrossRef » PubMed » Google Scholar

28. Gao P, Rush BD, Pfund WP, Huang TH, Bauer JM, et al. (2003) Development of a supersaturable SEDDS (S-SEDDS) formulation of paclitaxel with improved oral bioavailability. J Pharm Sci 92: 2386-2398. » CrossRef » PubMed » Google Scholar

29. Gao ZG, Choi HG, Shin HJ, Park KM, Lim SJ, et al. (1998) Physicochemical characterization and evaluation of a microemulsion system for oral delivery of cyclosporin A. Int J Pharm 161: 75-86. » CrossRef » PubMed » Google Scholar

30. Giliyar C, Fickstad DT, Tyavanagimatt S (2006) Challenges and opportunities in oral delivery of poorly-soluble drugs. Drug Deliv Technol 6: 57-63. »CrossRef » PubMed » Google Scholar

31. Gomez-Orellana I (2005) Strategies to improve oral drug bioavailability. Expert Opin Drug Deliv 2: 419-433. » CrossRef » PubMed » Google Scholar

32. Hansen T, Holm P, Rohde M, Schultz K (2005) In vivo evaluation of tablets and capsules containing spray-dried o/w-emulsions for oral delivery of poorly soluble drugs. Int J Pharm 293: 203-211. » CrossRef » PubMed » Google Scholar

33. Hassan HA, Al-Marzouqi AH, Jobe B, Hamza AA, Ramadan GA (2007) Enhancement of dissolution amount and in vivo bioavailability of itraconazole by complexation with beta-cyclodextrin using supercritical carbon dioxide. J Pharm Biomed Anal 45: 243-250. » CrossRef » PubMed » Google Scholar

34. Hayden FG, Jennings L, Robson R, Schiff G, Jackson H, et al. (2000) Oral oseltamivir in human experimental influenza B infection. Antivir Ther 5: 205213. » CrossRef » PubMed » Google Scholar

35. Hickey MB, Peterson ML, Scoppettuolo LA, Morrisette SL, Vetter A, et al. (2007) Performance comparison of a co-crystal of carbamazepine with marketed product. Eur J Pharm Biopharm 67: 112-119. »CrossRef » PubMed » Google Scholar

36. Hulsmann S, Backensfeld T, Bodmeier R (2001) Stability of extruded 17 ssestradiol solid dispersions. Pharm Dev Technol 6: 223-229. » CrossRef » PubMed » Google Scholar

37. Hulsmann S, Backensfeld T, Keitel S, Bodmeier R (2000) Melt extrusion - an alternative method for enhancing the dissolution rate of 17 beta-estradiol hemihydrate. Eur J Pharm Biopharm 49: 237-242. » CrossRef » PubMed » Google Scholar

38. Hussein K, Turk M, Wahl MA (2007) Comparative evaluation of ibuprofen/ beta-cyclodextrin complexes obtained by supercritical carbon dioxide and other conventional methods. Pharm Res 24: 585-592. »CrossRef » PubMed »Google Scholar

39. Kang BK, Lee JS, Chon SK, Jeong SY, Yuk SH, et al. (2004) Development of self-microemulsifying drug delivery systems (SMEDDS) for oral bioavailability enhancement of simvastatin in beagle dogs. Int J Pharm 274: 65-73. » CrossRef » PubMed » Google Scholar

40. Keck CM, Muller RH (2006) Drug nanocrystals of poorly soluble drugs produced by high pressure homogenisation. Eur J Pharm Biopharm 62: 3-16. $»$ CrossRef » PubMed » Google Scholar

41. Kerc J, Srcic S, Knez Z, Sencar-Bozic P (1999) Micronization of drugs using supercritical carbon dioxide. Int J Pharm 182: 33-39.» CrossRef » PubMed » Google Scholar

42. Kesisoglou F, Panmai S, Wu Y (2007) Nanosizing—oral formulation development and biopharmaceutical evaluation. Adv Drug Deliv Rev 59: 631-644. » CrossRef » PubMed » Google Scholar

43. Kim JS, Kim MS, Park HJ, Jin SJ, Lee S, et al. (2008) Physicochemical properties and oral bioavailability of amorphous atorvastatin hemi-calcium using spraydrying and SAS process. Int J Pharm 359: 211-219. » CrossRef » PubMed » Google Scholar

44. Kompella UB, Koushik K (2001) Preparation of drug delivery systems using supercritical fluid technology. Crit Rev Ther Drug Carrier Syst 18: 173-199. »CrossRef » PubMed » Google Scholar

45. Kumar VV, Chandrasekar D, Ramakrishna S, Kishan V, Rao YM, et al. (2007) Development and evaluation of nitrendipine loaded solid lipid nanoparticles: Influence of wax and glyceride lipids on plasma pharmacokinetics. Int J Pharm 335: 167-175. » CrossRef » PubMed » Google Scholar

46. Lawrence MJ, Rees GD (2000) Microemulsion-based media as novel drug delivery systems. Adv Drug Deliv Rev 45: 89-121. CrossRef » PubMed » Google Scholar

47. Lee S, Nam K, Kim MS, Jun SW, Park JS, et al. (2005) Preparation and characterization of solid dispersions of itraconazole by using aerosol solvent extraction system for improvement in drug solubility and bioavailability. Arch Pharm Res 28: 866-874. » CrossRef » PubMed » Google Scholar

48. Leonardi D, Barrera MG, Lamas MC, Salomon CJ (2007) Development of prednisone:polyethylene glycol 6000 fast-release tablets from solid dispersions: solid-state characterization, dissolution behavior, and formulation parameters. 
Citation: Krishnaiah YSR (2010) Pharmaceutical Technologies for Enhancing Oral Bioavailability of Poorly Soluble Drugs. J Bioequiv Availab 2: 028-036. doi:10.4172/jbb.1000027

AAPS PharmSciTech 8: E108. »CrossRef » PubMed » Google Scholar

49. Li HL, Zhao XB, Ma YK, Zhai GX, Li LB, et al. (2009) Enhancement of gastrointestinal absorption of quercetin by solid lipid nanoparticles. J Control Release 133: 238-244. »CrossRef » PubMed » Google Scholar

50. Liebenberg W, de Villiers MM, Wurster DE, Swanepoel E, Dekker TG, et al. (1999) The effect of polymorphism on powder compaction and dissolution properties of chemically equivalent oxytetracycline hydrochloride powders. Drug Dev Ind Pharm 25: 1027-1033. » CrossRef » PubMed » Google Scholar

51. Lipinski CA, Lombardo F, Dominy BW, Feeney PJ (2001) Experimental and computational approaches to estimate solubility and permeability in drug discovery and development settings. Adv Drug Deliv Rev 46: 3-26. » CrossRef »PubMed » Google Scholar

52. Liu H, Zhou LL, Wei LL, Hong G, Nie SF, et al. (2007) Preparation of budesonide-poly (ethylene oxide) solid dispersions using supercritical fluid technology. Drug Dev Ind Pharm 33: 959-966. » CrossRef » PubMed » Google Scholar

53. Luo Y, Chen DW, Ren LX, Zhao XL, Qin J (2006) Solid lipid nanoparticles for enhancing vinpocetine's oral bioavailability. J Control Release 114: 53-59. »CrossRef » PubMed » Google Scholar

54. Mauro VF (1993) Clinical pharmacokinetics and practical applications of simvastatin. Clin Pharmacokinet 24: 195-202. »CrossRef » PubMed » Google Scholar

55. Mehnert W, Mader K (2001) Solid lipid nanoparticles: production, characterization and applications. Adv Drug Deliv Rev 47: 165-196. »CrossRef » PubMed » Google Scholar

56. Merisko-Liversidge E, Liversidge GG, Cooper ER (2003) Nanosizing: a formulation approach for poorly-water-soluble compounds. Eur J Pharm Sci 18: 113-120. » CrossRef » PubMed » Google Scholar

57. Milano G, Ferrero JM, Francois E (2004) Comparative pharmacology of oral fluoropyrimidines: a focus on pharmacokinetics, pharmacodynamics and pharmacomodulation. Br J Cancer 91: 613-617. »CrossRef » PubMed » Google Scholar

58. Miller LA, Carrier RL, Ahmed I (2007) Practical considerations in development of solid dosage forms that contain cyclodextrin. J Pharm Sci 96: 16911707. »CrossRef » PubMed » Google Scholar

59. Mohammed AR, Weston N, Coombes AGA, Fitzgerald M, Perrie Y (2004) Liposome formulation of poorly water soluble drugs: optimisation of drug loading and ESEM analysis of stability. Int J Pharm 285: 23-34. » CrossRef » PubMed » Google Scholar

60. Moribe K, Tozuka Y, Yamamoto K (2008) Supercritical carbon dioxide processing of active pharmaceutical ingredients for polymorphic control and for complex formation. Adv Drug Deliv Rev 60: 328-338. »CrossRef » PubMed » Google Scholar

61. Muchow M, Maincent P, Muller RH (2008) Lipid Nanoparticles with a Solid Matrix (SLN, NLC, LDC) for Oral Drug Delivery. Drug Dev Ind Pharm 34: 1394-1405. » CrossRef » PubMed » Google Scholar

62. Muller RH, Jacobs C, Kayser O (2001) Nanosuspensions as particulate drug formulations in therapy. Rationale for development and what we can expect for the future. Adv Drug Deliv Rev 47: 3-19. » CrossRef » PubMed » Google Scholar

63. Muller RH, Keck CM (2004) Challenges and solutions for the delivery of biotech drugs-a review of drug nanocrystal technology and lipid nanoparticles. J Biotechnol 113: 151-170. »CrossRef » PubMed » Google Scholar

64. Muller RH, Mader K, Gohla S (2000) Solid lipid nanoparticles (SLN) for controlled drug delivery - a review of the state of the art. Eur J Pharm Biopharm 50: 161-177. » CrossRef » PubMed » Google Scholar

65. Muller RH, Runge S, Ravelli V, Mehnert W, Thunemann AF, et al. (2006) Oral bioavailability of cyclosporine: Solid lipid nanoparticles (SLN (R)) versus drug nanocrystals. Int J Pharm 317: 82-89. » CrossRef » PubMed » Google Scholar

66. Paradkar A, Maheshwari M, Kamble R, Grimsey I, York P (2006) Design and evaluation of celecoxib porous particles using melt sonocrystallization. Pharm Res 23: 1395-1400. » CrossRef » PubMed » Google Scholar

67. Pasquali I, Bettini R, Giordano F (2008) Supercritical fluid technologies: an innovative approach for manipulating the solid-state of pharmaceuticals. Adv Drug Deliv Rev 60: 399-410. » CrossRef » PubMed » Google Scholar

68. Patel D, Sawant KK (2007) Oral bioavailability enhancement of acyclovir by self-microemulsifying drug delivery systems (SMEDDS). Drug Dev Ind Pharm 33: 1318-1326. »CrossRef » PubMed » Google Scholar

69. Ranpise NS, Kulkarni NS, Mair PD, Ranade AN (2010) Improvement of water solubility and in vitro dissolution rate of aceclofenac by complexation with betacyclodextrin and hydroxypropyl-beta-cyclodextrin. Pharm Dev Technol 15: 6470. »CrossRef » PubMed » Google Scholar

70. Remenar JF, Morissette SL, Peterson ML, Moulton B, MacPhee JM, et al. (2003) Crystal engineering of novel cocrystals of a triazole drug with 1,4-dicarboxylic acids. J Am Chem Soc 125: 8456-8457. »CrossRef » PubMed » Google Scholar

71. Repka MA, Majumdar S, Kumar Battu S, Srirangam R, Upadhye SB (2008) Applications of hot-melt extrusion for drug delivery. Expert Opin Drug Deliv 5: 1357-1376. » CrossRef » PubMed » Google Scholar

72. Roth W, Setnik B, Zietsch M, Burst A, Breitenbach J, et al. (2009) Ethanol effects on drug release from Verapamil Meltrex, an innovative melt extruded formulation. Int J Pharm 368: 72-75. » CrossRef » PubMed » Google Scholar

73. Sakaeda T, Okamura N, Nagata S, Yagami T, Horinouchi M, et al. (2001) Molecular and pharmacokinetic properties of 222 commercially available oral drugs in humans. Biol Pharm Bull 24: 935-940. » CrossRef » PubMed » Google Scholar

74. Salmaso S, Bersani S, Elvassore N, Bertucco A, Caliceti P (2009) Biopharmaceutical characterisation of insulin and recombinant human growth hormone loaded lipid submicron particles produced by supercritical gas microatomisation. Int J Pharm 379: 51-58. »CrossRef » PubMed » Google Scholar

75. SencarBozic P, Srcic S, Knez Z, Kerc J (1997) Improvement of nifedipine dissolution characteristics using supercritical CO2. Int J Pharm 148: 123-130. »CrossRef » PubMed » Google Scholar

76. Serajuddin ATM (1999) Solid dispersion of poorly water-soluble drugs: Early promises, subsequent problems, and recent breakthroughs. J Pharm Sci 88: 10581066. »CrossRef » PubMed » Google Scholar

77. Sethia S, Squillante E (2002) Physicochemical characterization of solid dispersions of carbamazepine formulated by supercritical carbon dioxide and conventional solvent evaporation method. J Pharm Sci 91: 1948-1957. » CrossRef » PubMed » Google Scholar

78. Sethia S, Squillante E (2004) Solid dispersion of carbamazepine in PVP K30 by conventional solvent evaporation and supercritical methods. Int J Pharm 272: 1-10. » CrossRef » PubMed » Google Scholar

79. Shah NH, Carvajal MT, Patel CI, Infeld MH, Malick AW (1994) Self-Emulsifying Drug-Delivery Systems (Sedds) with Polyglycolyzed Glycerides for Improving in-Vitro Dissolution and Oral Absorption of Lipophilic Drugs. Int $\mathbf{J}$ Pharm 106: 15-23. » CrossRef » PubMed » Google Scholar

80. Shan N, Zaworotko MJ (2008) The role of cocrystals in pharmaceutical science. Drug Discov Today 13: 440-446. »CrossRef » PubMed » Google Scholar

81. Shefter E, Higuchi T (1963) Dissolution Behavior of Crystalline Solvated and Nonsolvated Forms of Some Pharmaceuticals. J Pharm Sci 52: 781-791. » CrossRef » PubMed » Google Scholar

82. Singh AK, Chaurasiya A, Awasthi A, Mishra G, Asati D, et al. (2009) Oral bioavailability enhancement of exemestane from self-microemulsifying drug delivery system (SMEDDS). AAPS PharmSciTech 10: 906-916. » CrossRef » PubMed » Google Scholar

83. Steckel H, Thies J, Muller BW (1997) Micronizing of steroids for pulmonary delivery by supercritical carbon dioxide. Int J Pharm 152: 99-110. » CrossRef » PubMed » Google Scholar

84. Stella VJ, Rajewski RA (1997) Cyclodextrins: their future in drug formulation and delivery. Pharm Res 14: 556-567. »CrossRef » PubMed » Google Scholar

85. Stozek T, Borysiewicz J (1991) The Bioavailability of Griseofulvin in Liposomes. Pharmazie 46: 39-41. » CrossRef » PubMed » Google Scholar

86. Suleiman MS, Najib NM (1989) Isolation and Physicochemical Characteriza- 


\section{Journal of Bioequivalence \& Bioavailability - Open Access \\ JBB/Vol.2 Issue 2}

tion of Solid Forms of Glibenclamide. Int J Pharm 50: 103-109. » CrossRef » PubMed » Google Scholar

87. Suresh G, Manjunath K, Venkateswarlu V, Satyanarayana V (2007) Preparation, characterization, and in vitro and in vivo evaluation of lovastatin solid lipid nanoparticles. AAPS PharmSciTech 8: 24. »CrossRef » PubMed » Google Scholar

88. Szente L, Szejtli J (1999) Highly soluble cyclodextrin derivatives: chemistry, properties, and trends in development. Adv Drug Deliv Rev 36: 17-28. »CrossRef » PubMed » Google Scholar

89. Tang B, Cheng G, Gu JC, Xu CH (2008) Development of solid self-emulsifying drug delivery systems: preparation techniques and dosage forms. Drug Discov Today 13: 606-612. »CrossRef » PubMed » Google Scholar

90. Tao T, Zhao Y, Wu JJ, Zhou BY (2009) Preparation and evaluation of itraconazole dihydrochloride for the solubility and dissolution rate enhancement. Int J Pharm 367: 109-114. » CrossRef » PubMed » Google Scholar

91. Uchino T, Yasuno N, Yanagihara Y, Suzuki H (2007) Solid dispersion of spironolactone with porous silica prepared by the solvent method. Pharmazie 62: 599603. »CrossRef » PubMed » Google Scholar

92. Vemavarapu C, Mollan MJ, Lodaya M, Needham TE (2005) Design and process aspects of laboratory scale SCF particle formation systems. Int J Pharm 292: 1-16. »CrossRef » PubMed » Google Scholar

93. Verreck G, Six K, Van den Mooter G, Baert L, Peeters J, et al. (2003) Characterization of solid dispersions of itraconazole and hydroxypropylmethylcellulose prepared by melt extrusion - part I. Int J Pharm 251: 165-174. »CrossRef » PubMed » Google Scholar

94. Vieth M, Siegel MG, Higgs RE, Watson IA, Robertson DH, et al. (2004) Characteristic physical properties and structural fragments of marketed oral drugs. $\mathrm{J}$ Med Chem 47: 224-232. »CrossRef » PubMed » Google Scholar

95. Vishweshwar P, McMahon JA, Bis JA, Zaworotko MJ (2006) Pharmaceutical co-crystal. J Pharm Sci 95: 499-516. » CrossRef » PubMed » Google Scholar

96. Wang L, Cui FD, Sunada H (2006) Preparation and evaluation of solid dispersions of nitrendipine prepared with fine silica particles using the melt-mixing method. Chem Pharm Bull 54: 37-43. »CrossRef » PubMed » Google Scholar

97. Wang LA, Cui FD, Hayase T, Sunada H (2005) Preparation and evaluation of solid dispersion for nitrendipine-carbopol and nitrendipine-HPMCP systems using a twin screw extruder. Chem Pharm Bull 53: 1240-1245. »CrossRef » PubMed » Google Scholar
98. Wang X, Michoel A, Van den Mooter G (2004) Study of the phase behavior of polyethylene glycol 6000-itraconazole solid dispersions using DSC. Int J Pharm 272: 181-187. »CrossRef » PubMed » Google Scholar

99. Wenlock MC, Austin RP, Barton P, Davis AM, Leeson PD (2003) A comparison of physiochemical property profiles of development and marketed oral drugs. J Med Chem 46: 1250-1256. »CrossRef » PubMed » Google Scholar

100.Won DH, Kim MS, Lee S, Park JS, Hwang SJ (2005) Improved physicochemical characteristics of felodipine solid dispersion particles by supercritical anti-solvent precipitation process. Int J Pharm 301: 199-208. »CrossRef » PubMed » Google Scholar

101.Wu HF, Lu CH, Zhou A, Min ZW, Zhang YL (2009) Enhanced Oral Bioavailability of Puerarin Using Microemulsion Vehicle. Drug Dev Ind Pharm 35: 138-144. »CrossRef » PubMed » Google Scholar

102. Yamanaka YJ, Leong KW (2008) Engineering strategies to enhance nanoparticle-mediated oral delivery. J Biomater Sci Polym Ed 19: 1549-1570. »CrossRef » PubMed » Google Scholar

103. Yang L, Chen L, Zeng R, Li C, Qiao R, etl al. (2010) Synthesis, nanosizing and in vitro drug release of a novel anti-HIV polymeric prodrug: Chitosan-Oisopropyl-5'-O-d4T monophosphate conjugate. Bioorg Med Chem 18: 117-123. »CrossRef » PubMed » Google Scholar

104. Yang L, Geng YH, Li H, Zhang Y, You JS, et al. (2009) Enhancement the oral bioavailability of praziquantel by incorporation into solid lipid nanoparticles. Pharmazie 64: 86-89. »CrossRef » PubMed » Google Scholar

105.Yasuji T, Takeuchi H, Kawashima Y (2008) Particle design of poorly watersoluble drug substances using supercritical fluid technologies. Adv Drug Deliv Rev 60: 388-398. »CrossRef » PubMed » Google Scholar

106.Yin YM, Cui FD, Mu CF, Choi MK, Kim JS, et al. (2009) Docetaxel microemulsion for enhanced oral bioavailability: Preparation and in vitro and in vivo evaluation. J Control Release 140: 86-94. »CrossRef » PubMed » Google Scholar

107. York P (1999) Strategies for particle design using supercritical fluid technologies. Pharm Sci Technolo Today 2: 430-440. »CrossRef » PubMed » Google Scholar

108. Yoshikawa M, Nishiyama S, Takaiti O (1995) Metabolism of dopamine prodrug, docarpamine. Hypertens Res 18: S211-213. »CrossRef » PubMed » Google Scholar 